\title{
The apparent contrariety
}

\author{
Francisc Gafton* \\ Faculty of Letters, "Alexandru Ioan Cuza" University, Bd. Carol I 11, 700506 Iași, Romania
}

\section{Article info}

History:

Received February 9, 2018

Published October 7, 2018

Key words:

society

religion

rite

mentality

science

\begin{abstract}
There are societies in which individual and social mentalities are deeply imbued with religion, which dominates as a philosophy of life, and which guides its followers from the most insignificant to the most important thoughts and acts. There, secular life is the faithful reflection of religious ideology, unfolding in the shadow of its ancestral and collective narratives. There, present and future celebrate a mystical past, which they replicate through a circular effort and in their own circumstances.

There are societies in which social life interferes little, if at all, with the religious one; where religion is merely tolerated, instead of being assimilated or consuming. There, religion is not an ideological guide, an all-leading factor and force, but only a reminiscent paradigm; there, present and future shape themselves as stages of an evolutive spiral.

A society to which religion imposes itself as a force that tends to perpetually conserve the status quo, opposing paradigm shifts in order to keep society on the uniform path of the imposed ideal; and a society that believes that since the fundamental reality is matter acting according to its internal laws, ideology appears, exists and becomes through and in the image of the material being subject to evolution, beyond its developments and avatars.
\end{abstract}

"Good and evil, reward and punishment, are the only motives to a rational creature: these are the spur and reins whereby all mankind are set on work, and guided."

(John Locke)

INDIVIDUAL AND COMmUnity. Naturally aggregated on genetic criteria, individuals come to formjust as naturally-a community. Within it, while instinctively searching for food and safety, the individual takes notice of the existence of others, and in relation to them he gradually gains self-awareness. This fact makes him understand-equally instinctively and intuitively-individualness and community, the relation between his own existential needs and those of the community, the benefits and shortcomings of the cooperation and competition with other individuals, within the boundaries of the community. Thus he finds out that individuals naturally tend towards satisfying their own needs by any means, while the community tends towards harmonizing, through compromise, the needs and interests of its constituent individuals and of the community itself, in consonance with the individual and social capabilities and values. At the same time, the exercise of natural relations between the human being and his environmentperceived, observed, interiorized and reflected as a whole to which the being belongs organically, and as a dominant factor-leads to the understanding of Nature's character as both environment and factor. In this way, the instinctive tendency to survive is transformed into a conscious attempt aimed in the same direction and with the same purpose, but within the framework of the community.

In turn-again, naturally -, owing its existence to observation, accumulation and memorization, reflection, communication, and horizontal and vertical transmission, the community structures itself systemically and comes to possess a set of helpful assets for a being without landmarks in an unfathomable world. Enacted and successfully exercised, offering efficient results and possible future solutions, subject

\footnotetext{
*Email address: algafton@gmail.com.
} 
to refinement, improvement and normation-all in virtue of the common and non-antagonistic goals of the components of society-those assets become both a way of knowing the world and a means of acting in it. Being efficient, trustworthy-even beyond many resilient doubts-, they become prescriptive and apt to regulate the entire life, as they are the insurer of consented, predictable action, but most of all subject to norms that are advantageous for the community. This is the moment when, acquiring the attributes of culture, the set of known facts, concepts, norms and patterns of action becomes ideology.

In this context, the social individual cannot place himself at the centre of the frame of reference (as he would suffer the blame and exclusion from the community), though neither can he place community on that position while completely ignoring himself (which would be a self-annihilating act). For this reason, any judgement of the social individual-from the perception through contrast of the other to the selfflattering illusion generated by the survival strategy (both conscious and subconscious) called altruismoscillates between self and other, between individual and social good, only because the self, the individual, cannot exist without the other and without the community. (In fact, above all other appearances, from anorganic to living matter, from the simplest unicellular being to the most complex one, gregariousness, sociality, or whatever one would name the result of the adhesive and cohesive forces constitutes one of the fundamental features, with both a structural and a functional nature.) In all social animals, the existence of the community depends on that of its individuals, and the individual development depends and is determined by the relation with the members of one's own community. In this framework of relatively tensioned concordance between the natural tendencies - of both the social individual and of the society-, personal experience is subsumed to the community and determined by its limits: whether the individual is subject to norms, or breaks them, or restructures them, or eludes them, ultimately he cannot simply ignore them; one way or another, he follows the patterns of the community in which he forms and exists, patterns that stem from the entirety of needs and interests of the community's determining factors.

Religion. Social life generates, orders, enacts, assimilates, improves and transmits its products. On the basis of faith (that is, of a complex state generated by the combined action of experience, memory, wishfulness and other effects of the electrochemical workings of the neural system in constant interaction with itself, with its own products, and with its environment) and as a result of the institutionalization of certain forms and structures, of some concepts, mentalities, ethical and moral projections, practices, etc., society transforms some of its cultural and ideological elements into religion. From a processualhistorical and comparative perspective, its forms and contents show it to be a necessary social institution, generated by the social-human evolutionary processes and by the actual needs that stem from them. As an epiphenomenon through which the individual is easily put in communion with society-which can thus fulfil its capital tendency towards coherence and homogeneity-, religion prompts both: a) the individual to serve, to give real existence, identity and fulfilment to society, b) the society to reciprocate in kind towards the individual. The individual feeds on the realizations of the community, while the community feeds on the high achievements of competent individuals and on the wishfulness of the others. In this respect, religion is a motor, coagulant, potentiator and conservative factor.

The fact that religious experience manifests itself in ways that are culturally determined, and that it contains individual inner experiences leads to the semblance that religion is a cultural and individual phenomenon. In fact, regardless of its degree of development, type or particular systemic aspects, regardless of the fact that it stems from and resonates within each individual-being capable of exhibiting infinite individual nuances-, religion casts and homogenizes individual experiences into collective ones, it generates, incorporates synthetically and represents social institutions, being both a social phenomenon and a social factor. No matter how particular and individual it might seem, it bursts from the collectiveness, it becomes whole through sharing, communion and institutionalization, the motivations and practices of the individuals being subsumed to those of the community.

In this way, religion is a means of resolving the tragical conflict between the individual and the social good, its resolution (or avoidance) occuring exclusively by means of the imagination of an ideal self, which 
conciliates the two and governs their mental and behavioural life, their needs and aims.

DEITY. By overcoming the merely passive perception and the intuitive-instinctive action, by valuing and potentiating the accumulated experience, the human being managed to deduct the principle from its forms of manifestation, to understand the relation of causality (not unlike, in fact, many other animal species) and passed from allegorization to symbolization. In this context, the collaborative-concurrential world in which he was living imposed as a survival solution the attempt to somehow manipulate reality (from imagining and imitating an archetype to imparting the sign with the initiating and motor attributes of action).

While, initially, human faith was matching the force of Nature-under the pressure of various needs and desiderata-, the development of the mind in the sense of understanding reality and comprehending, in ever more detail, the complexity of Nature led to the formation of processes and means parallel to the actual reality. In this way, the spring, sky, tree and animal were attributed human traits such as arbitrariness and normativity, tolerance and will, then charged with symbolic values. Considering that the part can stand for the whole, that the simulacrum can generate the archetype, or desiring for the death of the individuals not to constitute their complete disappearance, it was considered that anything may be used as long as adequate means are devised. A few grains embodied the desired harvest, the watering of the earth was meant to bring rain, and the forebears had to be working for the benefit of their living descendants.

By replacing natural forces with primary gods, man took the first step from a relatively passive position to a somewhat active one. Gods were endowed with features and attributes in accordance to the measure and image of the cultural-mentalitary development of the societies, of the social experiences and desiderata that had produced them. As in the case of any cultural product, what, how, where and why a certain god was created determined the details of its structures, actions and interactions, a fact that devoided gods of any primary cosmic force, converting them into knowers of the nuanced laws and effects of said forces, into speculators of the processes of the world, according to their specific individual traits. At the same time, whether invested with Nature's fundamental attribute, that of creator and lawmaker, or in a position of governors and operators, capable of using correctly, of eluding, or of successfully confronting the objective laws of reality, this step led to the separation of the gods from Nature, and their escape from under its absolute dominance (and implicitly, their descent from universality to the particular domain).

Created in the image of the community and inherently belonging to it-that is, being projections of the social life and practice, of mentality and culture, of the concrete and particular ideals and aspirations of the community-, the gods become specific factors and collective ideals. Thus, necessarily and ineluctably, like humans, gods come to fight for existence, being subject to selection; the apparent ideological conflict between them is - truly and essentially - a subsistential one, reflecting the same struggle of the human being. (Of course, the development of social relations leads to a part of the biological aspect generating the ideological aspect, survival-and particularly immortality—referring not only to the biological level, but most of all to the mentalitary-ideological one-only apparently and illusionarily easier to reach.)

Since gods were somewhat in solidarity with the community and different from the gods of other communities, the essence of their function and value for the community, of the relation between the individuals and the community to them had to be expressed through a creed-a form of covenant through which the community proclaims the god and declares its obedience, thus triggering his protection and good will. The relation appears as symbiotic: the collective mind devises the god, attributes him traits and norms (whether moral, behavioural, valuational) and endows him with capabilities for knowledge and action, all in exchange for the validation of the expectations concerning survival and perpetuation. At the same time, this proclaiming of the creed leads to the institutionalization acquiring the special form of confession, which may lead to an increased cohesion of the community.

For this reason, in spite of formal, organizational, mentalitary, moral, and axiological differences between communities, like people, gods have the same functions, values and relations, fulfilling the same human needs. For, regardless of the ideological or evolutive discrepancies between the various perspectives 
of the communities, the human being has always attempted to effectively intervene in the course of the world to which he belongs or which he imagines, through actions meant to manipulate the factors and actions he believes his durability to depend on.

MAN. Inclined to operate with the intuitive-affective judgement, pursuing desiderata generated by immediate and apparent needs or by the tendency to exercise (often manneristically) his attributes and habits, and almost entirely unwilling to understand general and objective needs, man rather considers things and processes not according to what and how they are and arrange themselves in the world, but to what and how they would best be useful to him, imagining that there is a purpose to their existence, namely that of serving him - the supreme being, creator of gods. In this context, the human being attempted to imitate the transactional pattern of Nature, evidently only to the extent he had understood it.

Thus appear practices of all sorts, enacting complicated mechanism that require various categories of mediators (gods of inferior ranks, spirits, ghosts, saints, prophets, priests), aiming at the communion with the ideal, in order to ensure survival and gain a form of immortality-through the eternity of divinity and of ideology. Although seemingly unimportant tricks, mechanistic and pseudo-logical, mystical, aberrant and phantasmagorical, which take advantage of rules that the very cheater creates and then deceives himself into believing they would have any sort of effect, they are effects of intuitive knowledge and primitive forms of action that are thought to influence the great actions of Nature. (This type of mental and behavioural approach also occurs in the "objective" plane of society.) The situation does not speak so much to the lack of knowledge about the structures and laws based on which Nature works and produces its usual effects, as to the rather low evolutive level on which the human being finds himself. A being rather alert to the appearances of his own world, interested at any cost in the immediate effects of actions-his own or not - that he believes concern him directly, and especially willing to perform any evasive maneuver on any reality perceived as antagonistic or merely inconvenient. A being not sufficiently evolved so as to permeate himself with the profound understanding of realities of fundamental rank, nor to follow the way in which natural order emerges and functions, so as to harmoniously integrate into it. For this reasongiven that nothing is structurally perfect and functionally infallible, the individual, the community, and the products of consciousness being ever under the sign of the becoming-, although the act itself persists, its values and functions become, which divulges its non-divine character.

When the structures of biological organisms run their course and become a source of irritation, of inefficiency, and even start to fall out of use, since eliminating and physically replacing them would require an enormous investment of energy, the usual solution of the living matter is to consequently adjust the structure to new functions, which are to fulfil new needs.

Infinitely more conservative than any other human creation, religion is, however, not lacking in adaptive abilities. Changes within environment, community, and mentality may lead to the decay of the causes and motivations that had brought a rite into existence, of its original meaning, all coming to be considered implausible, outdated, etc. The result can be the revision of the interpretations, meanings and values, according to the new present, but the forms will persist and will continue to partially determine the contents.

This is why many - if not all — of the behaviours and customs particularly active, of the elements in the common mentality, the clichés, the various practices (starting with divination, through social convention, and ending with diplomatic rituals) are the syncretic results-formally perennial, though perishable in content-of the mentality and ideological activity subject to magicalmystical factors.

RITE. As the result of a string of arduous adaptations to the requirements of the environment, the human being passed from the simple notice of rhythms and cycles, of ordered and causal successions, then of the existence of various external factors, limiting and determining, to the understanding-albeit superficialof the essentially implacable, and only apparently or accidentally malleable, character of those factors. 
In the context of this understanding of the environment, and in the attempt of obtaining certain beneficial results (already generated naturally or easy to imagine by extrapolating the model provided by Nature), human nature acquired the tendency to believe in transcendence, which the human being and his consciousness-burdened by defects, imperfections and deficiencies_-imagined as being endowed with the means to ensure his survival and reproduction, both as organism and as consciousness. Putting then meanings and values into things and processes, the human being came to construct a rather enantiomerical means of fulfilling certain needs, namely the rite-the sequential act, systemically organized, generated by imitation instincts (results of the workings of mirror neurons), which uses defined mechanisms and instruments. Gradually, from the attempt to somehow reproduce natural processes it has passed to shortcircuiting them, simultaneously with the passing from the belief that the human being is consubstantial with Nature, in front of which he is completely helpless and at most opportunistic, to that he is different from Nature, unique, wonderful, etc., and that the entire Universe conspires in helping him achieve his needs, reality itself being a concoction of the human mind! Mysticization-an attribute acquired through a secondary and twisted effect of evolution-thus makes man to exit from under the dominion of the evolving Nature, to imagine himself as unique and potentially immutable.

Urged on and modulated by concrete needs, led by a primary type of perception and imitation of reality, man creates a whole system of rituals based on the intuitive understanding of the fact that: a) the apparent level is generated by the fundamental one, which is not exactly and accurately reflected, but which can be somewhat influenced through actions operating at the apparent level, by imagining the underlying processes; $\mathrm{b}$ ) what happens at the surface may produce, trigger, catalyse or even modify the fundamental level. From here there was less than a step to understanding that renouncement and death are necessary to continuity and life.

SACRIFICE. The act of sacrifice is rooted in observations of certain natural mechanisms governed by the principles of efficiency and transaction, which set in motion the entire Nature. Through such practices, communities that are transiting from genetic gregariousness to cultural socialization follow their survival and reproduction instinct, enacting a magical-mystical paradigm, evolutively acquired. The goal is to provoke the appearance or maintenance of a beneficial and favourable state, to banish an adverse present or a presumably unwanted future, to repair a bad past, to balance the relationship between their state and that of the god (either from whose cornucopia it is taken, or to whom a compensation is granted), to prevent the appearance of a disequilibrium (thanking the god for what he had given), to fulfil, in advance or not, compensating a favour or a future solicitation or loss to which he will be subjected.

The nature, state and symbolic value of the sacrificed object are directly connected to the type, means and purpose of the sacrifice. Compared to other kind of rites (such as prayer, which-characterized by homeorhesis-is the act of the phenotype assuming the dynamics that had concretized it, bringing it into existence), homeostatic, the sacrifice is the dream of the genotype to maintain its identity unaltered.

Objects, beings or statuses can be sacrificed; both pure, just, bringing good and benefits to the community, and impure, unjust, bringing bad and misfortune. Concerning this aspect, even though things may appear to be clear, they do not lack complexity. In general, the first class is used to ask for favours or positive states, that is, in exchange for something good the divinity is offered something precious, a clean gift. Similarly, atonement, purification, and expulsion of bad are brought about through the removal of impure and nefarious elements of the community. In the first case, the pure fruit of the community is offered, which means that a part of the good is given up, while in the second, the community cleans itself implicitly, eliminating - through the very act of sacrifice - a part of the bad things from within.

Still, this parallel does not follow all the way through, as the applications are not linear and uniform, since the essence of magical-religious thought searches the depths in other ways and impose other appearances. In case of great disasters falling upon the community, although a purification sacrifice is operated, it is imperious that it is followed by one through which the clean foundations of the desired future are laid, a fact accomplished by sacrificing the good, clean and impeccable, thus converted into an 
exemplary sacrifice. On the basis of the same type of magical-religious considerations, some practices aim at protecting or absolving the villain and ill bearer. Nevertheless, the procedure of sparing the unclean and nefarious is occasional and exceptional, the community normally practising selection and understanding that keeping that element inherently leads to the perpetuation of that type of action, even if only through the mere biological reproduction of such an individual.

Is this transposition (the sacrifice of the apt and valuable, and the protection of the weakling and sinner) a magical attempt to avoid an anticipated fate deserved by the latter, in the context of not fully controlling the laws of the sacred and the imprevisibility of the divine action and of the possible identificationconscious or not-of the former with the latter? If so, such a practice makes human action to become the educator of the divine one, a sort of precedent-model through which divinity and even the lawfulness or the sacred acquire tolerance towards the bad and nefarious acts, a double standard that eludes the act and only regards the man, the intented consequence being tolerance for one's own mistakes, which the potentially positive or somewhat privileged members may commit.

In any case, this situation reveals the disappearance of the primary being-which, in order to fulfil his needs, seeks to follow and faithfully reproduce the actions of Nature-and the appearance of Man-who dictates to the divinity. Ceasing to think of himself as a worthless product of Nature, the human being comes to believe that it can modify reality in the image of his objective and subjective needs and goals.

This last aspect also occurs in scientific thought, but there one recognizes the permissions and limits of objective reality, extracts conclusions through enacting the norms of the scientific paradigm, and acts accordingly. On this side, however, one presumes factors of mystical nature and imagines limitations and interdictions made by the human mind, based on figments of its own imagination. Such logic and action, through which the objective laws of Nature and those invented by man are interpreted and twisted to annihilation - all in order to obtain a favourable result, but necessarily justified by the appearance of the emanation from the incontestable and unanimously accepted authority (divinity, law, etc.) (just broken, corrected and reinstituted in a perfectly arbitrary manner) - is typically human in the highest degree: the ever-dismissed feature that truly identifies, singles out and defines this primate. This model is generally applied, at the level of both individual and social consciousnesses. Besides the fact that such a practice indicates the way in which man handles his relationship with any alterity, most important is the fact that the trick reveals who is, in fact, the creator of the gods so treated. Surely, one can negotiate with a god in human terms, while the all-creating Nature can only be obeyed and followed. After all, anthropocentrism, the dear child of human hypocrisy-sometimes parasiting, therefore dissolutive, other times social lubricant, therefore necessary, yet other times instinctive fear, thus genetic acquisition-is the fuel, devourer and pandant of all types of social actions.

Whether it solicits a benefit or an advantage, or it expiates, regrets or thanks, the sacrificial rite follows from observation of the transactional system of Nature. The deepening of observations leads to understanding the substitutive nature of objects, processes and states, ultimately actioning perfidly through the reinvesting of the rite with valences that, at the same time, have to calm down a conscience agitated by the fear of unskilled intervention in the order of the world, and to ensure the effectiveness of the rite. So it happens that, after the sacrificial killing of a living being, humans ritualistically affirm their "respect" for it, thank it for the "consent" of sacrificing itself for them, after which they use it freely; so it happens that the supplicant or penitent believes that he may accumulate, borrow and gain good will, and therefore can also "spend" it-in advance or subsequently.

In fact, rites of initiation, accommodation, investment and preservation, through which society acts in the direction of the continuity of paradigm and of recognizing its members, all stem from the same observations of the natural circuits, though they are distorted through human interventions that concoct by imagining and forge by torsioning hermeneutic mechanisms supposed to tolerantly justify their conduct, 
and to ensure plenitude in life and infinity in lastingness.

НуротнеSIS. Every genetic, social, cultural and mentalitary community in a given space and at a given time has its own existential needs, ideals and projections that organically proceed from its appearance, development, endurance and historical becoming. The natural, dominant tendency of any such organizational structure is to conceive itself at the centre of the frame of reference, perfect as compared to other such structures-possibly seen as errors or wanderings. Even when the ideals and projections of the community target the modification of a state, the perspective is centripetal since the overwhelming tendency is the correction of a deviation from a state conceived as original, "golden", "true", etc., or at least the adoration, i.e. the precise-or at least reasonable-following of an exemplary internal model. Although each stage in the evolution of the community is but a temporary solution, the tendency to avoid the modification of the existing mental state targets continuity-understood more as identity than as organic and coherent evolution. The fact imposes that the momentarily satisfactory solution be in agreement with the ideals of the past and attract the colaborative validation of future moments. On the one hand, aside from particularities-inherently relevant for the concrete environment that had generated that organism, and often differentiating under a qualitative aspect-, the identity between the need and the solution reveals a similar mental paradigm. On the other hand, the stability of the society is ensured by keeping its essences untouched, the adaptations concerning just the adjustments required by the conjunctural demands of the environment.

Unfolded in various degrees of intension and extension from the anorganic to the organic level, attributes such as perception, storage, memorization, efficient action, economical reaction and accommodation reflect the interactional capabilities of matter, being essential for the evolving living beings thus naturally endowed. The interactional function, in the conditions of the environment, is able to generate a plethora of hierarchized structural-functional effects, while maintaining the original identity. But this identity, the community or the structural likeness, the closeness of the path, the functional similarity do not necessarily lead to disjunctive superposition. In fact, looking at a global (social) level and discerning the mechanisms that animate the elementary (individual) level, one ultimately notices that the appearance and development of the religious and scientific paradigms can be traced back to the same profound primary needs, being generated by homologous mechanisms.

At the level of mere survival, the instincts and affective judgements may generate effective actions and interventions, the magical-mystical and religious paradigm being indispensable. Due to their syncretism, the human mind and action attempts to determine the relation between imagined supernatural factors, then between those and the effects of their existence and action, after which they attempt to influence the aforementioned factors directly-often through the action of various somewhat cognate or linked elements (attributes, sensibilities, aphines, derivatives, effects, representations, etc.). Based on experience, correlations, interpretations and desiderata, pre-scientific and intuitive-empirical knowledge attempts to act by inducing acts with consequences that try to orient presupposed factors, with the goal of obtaining certain desired effects.

In the complex planes of existence, the attempt to penetrate and understand the objective laws of reality imposes its structural-functional conceptualization, and leads to a paradigm based on validated causal conjectures, with the following of the consequence of actions with the state and dynamics of reality. Compared to the narratives considered mythical, mystical or any other way, the mental constructions that imagine black holes as wormholes that connect one universe to the other-all universes being connected between them and subject to a supreme law, based on quantum mechanics and general relativity-may also be considered narratives fed by speculations brought to coherence by the human mind. The fundamental difference, though, is that the latter follow from an entirely different conceptual paradigm, whose bases are not imaginative but anchored in the positive data of the objective reality.

This fact shows that both religion and science are products of the human mind; what sets them apart 
(though not absolutely and completely, since the same anatomic-physiological structure and the same environment generated both) are the means and paradigms employed to perceive, conceive and act. Religion finds out, decrees and acts by conceiving ad-hoc a suprareality that manipulates or blurs reality, walking along the infinite path of the inventing and interpreting mind. On the other hand, proceeding along an evolutive path that successively opens horizons, science searches, proposes and operates by observing, measuring and obeying the instruments of reason, in order to discover (positive and negative) certitudes.

The two dizygotic products of the human mind-one conservative and ritualized, much like the autoreproduction of genetic material, the other dynamic and flexible, similar to the evolution of phenotype; one sedimented and turned instinctual, the other ever novel and untameable-are equally fascinating and necessary at the social level. Their twinship makes them co-resonate, as they are equally in a harmony of complementarity and in a game of opposability; often assonant, rarely consonant, never entirely dissonant. This state is beneficial —even only because it exercises two natural and organic activities and productsand constitutes an objective necessity, such as that of concurrent forces or of conjunct elements that, through a difference of potential, generate energy. Seldom in the same space as science, necessarily beyond it, religion is a form of knowledge and pre-scientific action. It is a hypothesis and a forerunner solution, acceptable in situations where science hesitates, errs, misjudges or is weak, so that the human being has in religion a temporary support, preventing it from wandering through the darkness of uncertaintyostensibly more desolate than the obscurity of the unknown. In fact, the supposition, the hypothesis constitutes not only the mirage that fascinates the human spirit or the path on which reason may advance, but the reflection of the way in which matter struggles evolutionarily, in its anorganic, organic and living aspects; from anorganic to organic and thence to life itself, ever "attempting", often "mistaking", ceaselessly "exercising" the principles in virtue of which it exists and functions, sometimes "stumbling upon" the optimal path of specifically fulfilling one or other principle.

Leading the human mind through the penance of learning, on the path from the abysmal and overwhelming chaos of ignorance to the tranquil and redemptive order of understanding, science treads in the wake of religion's fulgurations, which dynamizes it in the act of transforming the unknown to known, gradually conceding the known, now depressurized and clarified by science, and gradually proceeding towards as yet unlit areas.

[Translated by Emanuel Gafton and Adina Chirilă] 